\title{
Reflexões bioéticas no atendimento odontológico ao paciente portador de HIV/AIDS
}

\section{Bioethical reflections on dental care for patients with HIV/AIDS}

\author{
Felipe de Souza Matos \\ Universidade Federal de Sergipe (UFS), Aracaju, Sergipe, Brasil. \\ felipe_smatos@hotmail.com
}

\section{Lucas Paixão Santana}

Universidade Tiradentes (UNIT), Aracaju, Sergipe, Brasil.

luquinhas_00@hotmail.com

\section{Mônica Silveira Paixão}

Universidade Federal de Sergipe (UFS), Aracaju, Sergipe, Brasil.

paixao.monicasilveira@gmail.com

Resumo: $O$ advento da AIDS trouxe consigo uma série de questóes éticas e legais envolvidas na prática odontológica. Apesar dos avanços científicos, como o emprego de medidas de controle de infecçáo, e da garantia de acesso aos serviços de saúde por determinação constitucional, atitudes consideradas discriminatórias e antiéticas, como o abandono e recusa de atendimento odontológico ao paciente infectado, acontecem ainda nos dias atuais. Diante disso, a conduta dos profissionais de saúde frente aos indivíduos portadores da doença tem sido amplamente discutida. Embora náo existam nas normas éticas da odontologia brasileira referências explícitas à questão da AIDS, dispositivos éticos, nacionais e internacionais, têm sido bastante utilizados para disciplinar algumas questóes pertinentes. Neste contexto, o objetivo desse trabalho é realizar, mediante revisão de literatura, uma análise e discussão dos aspectos bioéticos envolvidos no atendimento odontológico a pacientes HIV soropositivos. Concluiu-se que o cirurgiáo-dentista tem a obrigação de tratar e atender estes pacientes, respeitando as questóes éticas, legais e sociais, constituindo-se atitude discriminatória a recusa de atendimento que leva em consideração unicamente o status sorológico do paciente, estando o profissional sujeito às penas previstas não só pelos conselhos profissionais, mas também pelos foros cível e criminal.

Palavras-chave: Bioética. Odontologia. HIV. AIDS.

Abstract: The advent of AIDS brought with it a series of ethical and legal questions involved in dental practice. Despite scientific advances through use of infection control measures and despite the guarantee of access to healthcare services, as determined by the Brazilian constitution, attitudes that can be 
considered to be discriminatory and antiethical, such as abandonment and refusal of dental care to infected patients still occur today. In this light, the conduct of healthcare professionals towards individuals with diseases has been widely discussed. Although there is no explicit reference to the question of AIDS in the Brazilian ethical standards for dentistry, national and international ethics mechanisms have been greatly used to regulate certain pertinent issues. Within this context, the aim of the present study was to analyze and discuss the bioethical factors involved in dental care for HIV-positive patients, through reviewing the literature. It was concluded that dental surgeons have the obligation to care for and treat these patients, while respecting ethical, legal and social issues, and that refusal to provide care solely on the basis of the patient's serological status would constitute a discriminatory attitude. In such an event, the professional would be subject to the penalties set forth not only by the professional councils but also by the civil and criminal courts.

Keywords: Bioethics. Dentistry. HIV. AIDS

Este trabalho pretende realizar, mediante revisão de literatura, uma análise e discussáo dos aspectos bioéticos envolvidos no atendimento odontológico a pacientes soropositivos para o human imunodeficiency vírus (HIV) ou com Síndrome da imunodeficiência adquirida (AIDS), com ênfase na responsabilidade ética e profissional do cirurgiáo-dentista ao lidar com tais pacientes.

A Síndrome da imunodeficiência adquirida (AIDS), cujo agente etiológico é o vírus HIV, representa um dos maiores e mais graves problemas sociais e de saúde pública já enfrentados pela humanidade (1). Definida como a manifestação clínica mais avançada da infecção pelo vírus HIV, a AIDS é caracterizada por uma imunossupressáo progressiva, resultando em uma maior suscetibilidade a infecçóes oportunistas, neoplasias e manifestaçóes neurológicas (2).

Desde o seu surgimento na década de 1980, o número de portadores de HIV, tanto assintomáticos quanto os que portam os sinais e sintomas da doença, vem crescendo assustadoramente. De acordo com o último boletim epidemiológico do Ministério da Saúde, desde o início da epidemia até junho de 2011, o Brasil tem registrado 608.230 casos de AIDS. Só em 2010, foram notificados 34.218 casos da doença no país, resultando em uma taxa de incidência de 17,9 casos por 100 mil habitantes (3). Conforme relatório do Programa conjunto das Naçóes Unidas sobre HIV/Aids (WHO/UNAIDS) de 2006, aproximadamente um terço de todas as pessoas vivendo com HIV na América Latina são brasileiras (4).

Diante disso, a conduta dos profissionais de saúde frente aos indivíduos portadores da doença tem sido amplamente discutida desde o início da epidemia (5). Dispositivos éticos, nacionais e internacionais, têm sido bastante utilizados 
para disciplinar algumas questóes pertinentes, embora não existam nas normas éticas da odontologia brasileira referências explícitas à questão da AIDS (6).

\section{$O$ advento da AIDS no mundo}

O advento da AIDS trouxe consigo uma série de questôes éticas e legais envolvidas na prática médico-odontológica. Apesar dos avanços científicos, com o emprego de medidas de controle de infecção, e da garantia de acesso aos serviços de saúde por determinação constitucional, atitudes consideradas discriminatórias e antiéticas, como o abandono e recusa de atendimento odontológico por parte do profissional, acontecem ainda nos dias atuais (7, 8). Segundo o estudo de Pires e outros, pacientes que revelaram ao dentista serem portadoras do vírus HIV tiveram 11,7 vezes mais dificuldades em obter atendimento odontológico (9).

Os primeiros casos de AIDS no mundo foram registrados no início dos anos 80, nos Estados Unidos, reconhecidos em pacientes homossexuais masculinos, os quais apresentavam um quadro clínico semelhante, de características próprias e com comprometimento do sistema imunológico, constatando que se tratava de uma nova doença, de etiologia infecciosa e transmissível (10). Inicialmente, suspeitou-se que houvesse alguma relaçáo entre a doença e o estilo de vida homossexual, já que os sintomas estavam presentes neste grupo, porém começaram a surgir novos casos entre heterossexuais e crianças recém-nascidas, constatando que a suspeita estava equivocada (6).

A velocidade com que a AIDS se disseminou, seu potencial de letalidade, por ser uma doença considerada incurável, e a forma equivocada como a doença era identificada e classificada (mistério médico, câncer gay, peste gay, pneumonia de homossexuais e castigo divino) preocupou todas as camadas da sociedade, gerando medo, preconceito e discriminação $(11,12)$. Poucos profissionais da saúde, inclusive os cirurgióes-dentistas, estavam dispostos a atender pacientes infectados pelo HIV, movidos pelo medo do desconhecido diante de uma nova doença. São muitos os relatos de indivíduos infectados que obtiveram recusa de atendimento por parte de cirurgióes-dentistas ao revelarem seu estado de soropositividade ao profissional, ou quando apresentavam sinais clínicos da doença, como perda de peso e alteraçóes na pele (8).

O perigo da transmissão ocupacional se tornou, então, uma das principais preocupaçóes das comunidades científicas na prática médico-odontológica, o que proporcionou um avanço na adoção de medidas de biossegurança, possibilitando a prevenção de transmissão de doenças infectocontagiosas no consultório odontológico. Com isso, houve um aumento gradativo, porém não linear, no índice de disposição dos cirurgiôes-dentistas a tratar tais pacientes, evidenciando maior conscientização dos profissionais e adequação nas medidas de biossegurança (13).

\section{A assistência aos pacientes com HIV/AIDS}


Apesar dos avanços, a discriminação continua existindo, embora de maneira mais camuflada, através do uso de argumentos técnicos ou outro tipo de esquiva que impedem o início ou a continuidade do tratamento por parte do profissional, e até mesmo através da cobrança de honorários aviltantes com o objetivo de inviabilizar o atendimento (14). A maioria desses profissionais justifica tais atitudes pela falta de preparo psicológico, medo de infecção pelo HIV e medo de perder outros pacientes quando estes soubessem que o seu cirurgiáo-dentista atendia pacientes publicamente conhecidos como aidéticos (12). Este comportamento tem gerado sentimento de humilhação e revolta nos pacientes infectados, o que leva os mesmos a não procurarem atendimento odontológico por medo de terem tratamento negado ou náo revelarem seu estado de soropositividade ao cirurgião-dentista a fim de obter tratamento indiscriminado (15).

Diante desse quadro, desde os primeiros anos do surgimento da epidemia na década de 1980, o dever de médicos e cirurgióes-dentistas, bem como de outros profissionais de saúde, no que se refere à assistência aos pacientes com HIV/AIDS, tem sido intensamente discutido (5). A Organização Mundial da Saúde (OMS), desde 1988, considera que "os odontólogos têm a obrigação humana e profissional de tratar e atender as pessoas infectadas com o HIV" (16).

No Brasil, em 1989, profissionais da saúde e membros da sociedade civil criaram, com o apoio do Departamento de doenças sexualmente transmissíveis, Síndrome da imunodeficiência adquirida e hepatites virais da Secretaria de Vigilância em Saúde do Ministério da Saúde (Departamento de DST, AIDS e hepatites virais/SVS/MS), a Declaração dos Direitos Fundamentais da Pessoa Portadora do Virus da Aids. Pela constituição brasileira, segundo este documento, os portadores do HIV, assim como qualquer cidadáo brasileiro, têm obrigaçóes e direitos garantidos. Entre eles: o direito à dignidade humana e o acesso à saúde pública, sem qualquer distinçáo; direito à participaçáo em todos os aspectos da vida social; proteção antidiscriminação com punição prevista por lei a toda açáo considerada discriminatória; privacidade assegurada por todos os serviços médicos e assistenciais, etc. (17).

\section{Dispositivos éticos disciplinares na relaçáo profissional-paciente}

No âmbito médico-odontológico, existem dispositivos éticos, nacionais e internacionais que, apesar de náo fazerem referência específica aos casos de HIV/AIDS, disciplinam algumas questôes pertinentes na relação profissionalpaciente, inclusive com relação ao abandono e recusa de atendimento ao paciente infectado (6).

Nesse contexto, a bioética, que nasceu em resposta da ética às novas situaçóes oriundas da ciência na área da saúde, é bastante utilizada como 
referência para regular as decisóes, as condutas e as políticas, a partir de um estudo sistemático das dimensôes morais, empregando uma variedade de metodologias éticas em um ambiente multidisciplinar $(1,18)$. Como um de seus primeiros resultados, pode-se considerar a formulaçáo dos Princípios da Bioética, que decorreram da criaçáo, pelo Congresso dos Estados Unidos, de uma comissão nacional encarregada de identificar os princípios éticos básicos que deveriam guiar a conduta humana no campo das ciências da vida e da saúde (6). São eles: o princípio da autonomia, da beneficência, da não-maleficência e da justiça, que constituem o ponto de partida obrigatório para qualquer discussáo, quando dilemas de ordem moral surgem na relaçáo profissionalpaciente.

É com base no princípio da autonomia que decorre a exigência do termo de consentimento livre e esclarecido (TCLE). Segundo este princípio, o cirurgiáo-dentista, ou qualquer outro profissional da saúde, deve respeitar a vontade dos pacientes, desde que estes estejam bem informados para a sua tomada de decisáo e plenamente capazes do ponto de vista psicológico. O princípio da beneficência requer do profissional o uso de toda a sua competência para o bem do paciente, minimizando os possíveis riscos e, como preconiza o princípio da náo-maleficência, sem acarretar dano intencional (19). E, para completar, o quarto princípio bioético, o da justiça, requer imparcialidade na distribuição dos benefícios e serviços de saúde, pois os iguais devem ser tratados igualmente. Dentro desta ótica, é inaceitável a discriminação de pacientes por razóes de ordem social, racial, religiosa ou de qualquer outra natureza, incluindo doenças como a AIDS (18).

A ética ou a deontologia, outra disciplina que explora as questóes éticas na relação profissional-paciente, também não são omissas sobre tais responsabilidades, diferindo-se da bioética na maneira como abordam os diferentes conflitos. Ao contrário da bioética, que atua segundo uma ética minimalista e não possui obrigatoriedade na resoluçáo dos conflitos, a deontologia utiliza-se de códigos, prescriçóes e respostas determinadas, valendose de mecanismos punitivos para disciplinar aqueles profissionais infratores de suas normas (20). A esse conjunto de prescriçóes que regulam os direitos e deveres dos profissionais e entidades ligadas à prática odontológica, dá-se o nome de Código de Ética Odontológica (CEO). Com validade em todo o território nacional, o CEO foi aprovado pela resoluçáo do Conselho Federal de Odontologia (CFO) 42/2003 e foi modificado pela resoluçáo CFO-71/2006 $(21,22,23)$.

Sáo preceitos éticos, adequadamente contemplados no CEO, exercer a Odontologia sem discriminaçáo de qualquer forma ou pretexto e zelar pela saúde e dignidade do paciente, independentemente de exercer a profissão em setor público ou privado (23). Tais preceitos vão ao encontro da constituição brasileira, que em seu artigo 196, confere a todos os cidadáos o direito adquirido e inalienável à saúde, enfatizando ainda mais a responsabilidade ética 
e profissional do odontólogo para com os pacientes portadores de HIV/AIDS $(12,24)$.

Com relação ao abandono ou recusa de atendimento odontológico ao paciente infectado, o CEO lembra aos profissionais que constitui infração ética "abandonar paciente, salvo por motivo justificável, circunstância em que serão conciliados os honorários e indicado substituto" e "deixar de atender paciente que procure cuidados profissionais em caso de urgência, quando náo haja outro cirurgião-dentista em condiçôes de fazê-lo", conforme os incisos VI e VII do artigo 7o, seção Ie capítulo V do documento (23). Assim, com exceção das situaçóes emergenciais, entende-se que, do ponto de vista dos direitos individuais, o cirurgiáo-dentista pode se recusar a atender o paciente com AIDS. Porém, nos casos em que o tratamento já foi iniciado, o abandono só pode ser realizado mediante motivo justificável, conciliando-se os honorários e indicando-se outro profissional que dê continuidade ao tratamento.

Apesar da grande preocupação com o risco de contaminação pelo vírus HIV no consultório odontológico, é importante informar que não há conhecimento de casos de transmissão de HIV/AIDS por aerossóis durante a atividade clínica odontológica (18). Por acidentes de trabalho, este risco é pequeno, porém concreto, a depender da gravidade do acidente e da carga viral do paciente (2). Para se ter uma ideia, o risco de infecçáo por HIV para a equipe odontológica é bem menor do que o risco de infecção pelo vírus da hepatite, com estimativas de $0,3 \%$ para o HIV, $1 \%$ a $10 \%$ para a hepatite C e $40 \%$ para a hepatite B (25).

Dessa forma, atitudes como recusa e abandono de tratamento odontológico ao paciente infectado se tornam ilógicas. Primeiro, porque o risco de contaminação é mínimo e praticamente zero, desde que medidas de precaução sejam aplicadas (12). Segundo, porque a maioria dos pacientes infectados é assintomática e desconhece ou não revela seu diagnóstico ao profissional, podendo este atender portadores do HIV sem mesmo o saber (2). Neste caso, a melhor conduta é considerar todos os pacientes como potencialmente infectados e adotar os procedimentos de biossegurança como rotina em qualquer atendimento, indiscriminadamente (1).

Outra questão ética bastante comum é a cobrança de honorários diferenciados para pacientes portadores de HIV ou AIDS, como forma de inviabilizar o atendimento ou de tirar proveito da situaçáo. O CEO relaciona alguns fatores que devem ser considerados na fixação dos honorários profissionais, entre eles, o conceito do profissional, a complexidade do caso, o tempo utilizado no atendimento, o custo operacional etc. Porém, náo está entre esses fatores o estado de soropositividade para o HIV ou a preexistência de qualquer outro tipo de enfermidade, conforme artigo 11 do capítulo VII do código (23). Portanto, a cobrança de valores diferenciados, que levem em consideração outras variáveis que não aquelas relacionadas no $\mathrm{CEO}$, constitui violação dos preceitos éticos. 
Já a imposição de horários especiais para atendimento a pacientes infectados por HIV náo pode ser considerada uma conduta discriminatória, uma vez que o CEO não faz referência a este assunto. Além disso, alguns protocolos recomendam que pacientes sabidamente infectados, seja por HIV ou hepatite $\mathrm{B}$, sejam atendidos no final do expediente, quando haverá mais tempo para a equipe odontológica realizar os procedimentos de desinfecção do equipamento utilizado (12).

No que diz respeito ao status sorológico do paciente, a pesquisa do anti-HIV, que confirma a infecçáo pelo vírus, é um recurso diagnóstico que o cirurgiáo-dentista tem competência legal para solicitar (lei no 5.081/1966, que regula o exercício da odontologia no Brasil), desde que indícios clínicos suficientes o justifiquem, respeitando-se a autonomia do paciente (18). Nestes casos, o CEO destaca que é dever do cirurgião-dentista guardar segredo profissional e sempre resguardar a privacidade do paciente referente à sua condição sorológica $\bigotimes$ capítulo III, artigo $5^{\circ}$, incisos VI e XIII $\otimes$, constituindo infração ética a sua revelação sem justa causa, de acordo com o artigo 10 do capítulo VI (23).

Vale ressaltar que os preceitos e normas aqui expostos, referentes ao $\mathrm{CEO}$, são de conhecimento obrigatório do profissional, não eximindo de pena o infrator que alegar ignorância ou má compreensão desse código, conforme o disposto nos artigos 40 e 43 do capítulo XVI (23). De acordo com o CEO, e dependendo da gravidade da infração, as penas cabíveis vão desde a advertência confidencial até a cassação do exercício profissional, embora possam ser aplicadas outras penas, nos foros cível e criminal, a partir da observância das demais regulamentaçóes aplicáveis $(1,20)$.

Também é importante destacar que, conforme o CEO, cabe ao cirurgiáodentista se manter atualizado a respeito dos conhecimentos profissionais, técnico-científicos e culturais necessários ao exercício pleno da função, buscando um maior conhecimento sobre a epidemia em seus aspectos técnicos, clínicos,

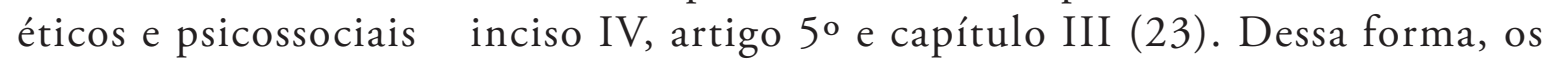
cirurgiôes-dentistas podem desempenhar um papel importante no atendimento global dos portadores de HIV/AIDS, garantindo um tratamento mais digno, humano e sigiloso e atuando como agentes de informação e orientaçáo para a comunidade (26).

\section{Conclusão}

O cirurgião-dentista tem a obrigação humana, ética e profissional de tratar e atender pacientes infectados pelo vírus HIV, desde queas necessidades do paciente se enquadrem em suas áreas de competência, sem qualquer tipo de discriminação, por determinação constitucional e em decorrência da criação de leis e normas éticas por órgáos específicos e competentes à sua área de atuação.

Legalmente, com exceçáo dos casos de emergência ou quando nenhuma 
outra instalação de tratamento está disponível, muitos profissionais de saúde bucal, em geral, náo sáo obrigados a aceitar um paciente em particular em seu consultório. Porém, a recusa de atendimento que leva em consideração unicamente o status sorológico do paciente é considerada uma atitude discriminatória, constituindo-se em infração ética prevista também nos foros cível e criminal.

A conduta mais segura, nesse caso, é adotar as normas universais de biossegurança e considerar todo paciente como possível portador de alguma doença infectocontagiosa. Além disso, os profissionais da odontologia devem adquirir conhecimentos básicos sobre a doença e buscar no CEO e nos conselhos profissionais amparo para solucionar questóes semelhantes as que foram aqui discutidas, a fim de manter uma postura ética e profissional mais adequada, garantindo um tratamento mais digno, humano e sigiloso aos seus pacientes.

\section{Referências}

1. Costa SM, Dias OV, Canela JR, Drumond JGF, Santa-Rosa TTA. Visão de discentes sobre atendimento a pacientes HIV/AIDS. Arquivos em Odontologia. 2009;45(1):10-15.

2. Correa EMC, Andrade ED. Tratamento odontológico em pacientes HIV/ AIDS. Revista Odonto Ciência. 2005;20(49):281-289.

3. Brasil. Ministério da Saúde. Secretaria de Vigilância em Saúde. Departamento de DST, Aids e Hepatites Virais [internet]. Boletim epidemiológico Aids/DST 2011 - [acesso em 09/Jun/2012]. Disponível em: http://www.aids.gov.br/ publicacao/2011/boletim_epidemiologico_2011

4. World Health Organization. United Nations Programme on HIV/AIDS (WHO/UNAIDS): report on the global AIDS epidemic. Genebra: WHO; 2006. 5. Garbin CAS, Garbin AJI, Tiano AVP, Silva FSJFB, Presta AA. Dentistry and HIV: university professors role in establishing a basis for judgment. BrazilianJournalof Oral Science. 2007;6(21):1326-1330.

6. Bechelani AAP. Aspectos penais e da bioética na transmissão do vírus HIV (monografia). Sáo Paulo: Faculdade de Direito de Presidente Prudente; 2003.

7. Brasil. Lei n.o 8.080, de setembro de 1990. Dispóe sobre as condiçóes para promoção, proteção e recuperação da saúde, a organização e o funcionamento dos serviços correspondentes e dá outras providências. Diário Oficial da União, Brasília, 21 set., 1990.

8. Garbin CAS, Garbin AJI, Moimaz SAS, Carmo MP. Bioética e HIV/AIDS: discriminação no atendimento aos portadores. Revista Bioética. 2009;17(3):511522 .

9. Pires MBO, Martelli Júnior H, Melo Filho MR, Cordeiro RS, Maia RC. Dificuldades percebidas por pacientes vivendo com HIV/Aids em obter tratamento odontológico. Arquivos em Odontologia. 2008;44(3):25-30. 
10. Brasil. Ministério da Saúde. Agência Nacional de Vigilância Sanitária. Serviços odontológicos: prevenção e controle de riscos. Brasília: Editora Anvisa; 2006.

11. Carvalho RB, Souza DA, Daleprane B, Batista RM, Gomes MJ. Projeto 'HIV com H de Humano': assistência odontológica a pacientes soropositivos um desafio ao preconceito. Saúde em Debate. 2011;35(88):128-137.

12. Discacciati JAC, Vilaça EL. Atendimento odontológico ao portador do HIV: medo, preconceito e ética profissional. Rev Panam Salud Pública/Pan Am J Public Health. 2009; 9(4):234-239.

13. Silva MDP, Marques CC, Oliveira Filho IG, Oliveira GN, Carneiro RM. Atenção odontológica a portadores de HIV/AIDS em Recife - Pernambuco, Brasil, 2005. Odontol. Clín,-cient. 2007;6(4):309-313.

14. Schuster MA, Collins R, Cunningham WE, Morton SC, Zierler S, Wong $\mathrm{M}, \mathrm{Tu} \mathrm{W}$, Kanouse DE, et al. Perceived discrimination in clinical care in a nationally representative sample of $\mathrm{HIV}$-infected adults receiving health care. Journal of General Internal Medicine. 2005;20(9):807-813.

15. Chen WT, Han M, Holzemer WL.Nurses knowledge, attitudes and practice related to HIV transmission in northeastern China. AidsPatientCareand STDS. $2004 ; 18(7): 417-422$.

16. Organização Mundial da Saúde. Responsabilidades éticas e profissionais dos cirurgióes-dentistas com respeito aos pacientes com HIV positivo e aos pacientes com aids. Actualidade Odontológica. 1988;30(1):37-39.

17. Brasil. Ministério da Saúde. Departamento de DST, Aids e Hepatites Virais [internet]. Declaração dos direitos fundamentais da pessoa portadora do vírus da Aids - [acesso em 09/Jun/2012]. Disponível em: http://www.aids.gov.br/ pagina/direitos-fundamentais

18. Francisconi CF [internet]. Aids e bioética [acesso em 04/Jul/2012]. Disponível em: http://www.bioetica.ufrgs.br/aids.htm

19. Galvão RCD, Silva LMM, Matos FR, Santos BRM, Galvão HC, Freitas RA. A importância da bioética na odontologia do século XXI. Odontol. Clín.Cient. 2010;9(1):13-18.

20. Paixão MS, Macedo IAB, Menezes Júnior LR. Código de ética odontológico brasileiro. FullDentistry in Science. 2011;2(8):125-138.

21. Pyrrho M, Prado MM, Cordón J, Garrafa V. Análise bioética do Código de Ética Odontológica brasileiro. Ciência \& Saúde Coletiva. 2009;14(5):19111918.

22. Brasil. Conselho Federal de Odontologia. Resolução do Conselho Federal de Odontologia n. ${ }^{\circ}$ CFO-42, de 20 de maio de 2003. Revoga o Código de Ética Odontológica aprovado pela Resoluçáo CFO-179/91 e aprova outro em substituição. RJ, 20 mai., 2003.

23. Brasil. Conselho Federal de Odontologia. Resolução do Conselho Federal de Odontologia n. ${ }^{\circ}$ CFO-71, de 06 de junho de 2006. Texto do Capítulo XIV alterado através da Resolução CFO-71, de 06 de junho de 2006, aprovada na 
CCIX Reunião Ordinária, de 25 de maio de 2006, que referendou as decisóes da CCVII Reunião Ordinária do Plenário do Conselho Federal de Odontologia - Assembléia Conjunta com os Conselhos Regionais de Odontologia, em Recife, nos dias 06 e 07 de abril de 2006. RJ, 26 jun., 2006.

24. Lelis RT. Estudo da ocorrência de atitudes discriminatórias na assistência à saúde de pessoas com HIV/AIDS (dissertação). Araçatuba: Universidade Estadual Paulista; 2006.

25. Alves EGR, Ramos DLP. Reflexões bioéticas e psicológicas sobre profissionais de saúde portadores de HIV/Aids. Revista Bioética. 2004;12(1):75-86.

26. Silva LN, Filho DLG, Ferreira DC. Infecção pelo HIV e a atividade laboral do portador: uma relação ética e legal na visão da odontologia do trabalho. DST - J Bras Doenças Sex Transm. 2007;19(1):35-44.

\section{Recebido: 30/07/2012 Aprovado: 29/11/2012}

